\title{
Degradation of Spectrin and band 3 protein
}

\author{
Manisha G. Audi \\ Associate Professor, Dept. of Biochemistry, Goa Medical College, Bambolim-Goa, India
}

*Corresponding Author:

Email: manishaaudi@ rediffmail.com

Received: $01^{\text {st }}$ May, 2017

Accepted: $06^{\text {th }}$ January, 2018

\begin{abstract}
Oxygen free radicals generated during radiation injury damage human erythrocyte membrane proteins including spectrin and band 3 protein. Results show an appreciable degree of spectrin and band 3 protein loss of about 55-65\% due to crosslinking, and proteolysis when sodium dodecyl sulphate polyacrylamide gel electrophoresis carried out on erythrocyte ghosts. Oxidative damage to membrane proteins lead to degradation of its cytoskeletal components.
\end{abstract}

Keywords: Spectrin, Band 3 protein, Erythrocyte ghosts, Oxygen free radicals.

\section{Introduction}

Oxygen free radicals have been implicated with tissue damage associated with radation injury, hyperbaric oxygen toxicity, ischaemia reperfusion injury as also with several degenerative diseases of nervous system and cellular ageing. ${ }^{1}$ Highly reactive free radicals like superoxide radical, hydroxyl radical, singlet oxygen and hydrogen peroxide occurring in vivo attack different biomolecules including phospholipids, proteins and nucleic acids leading to widespread functional and structural derangement of cells. ${ }^{2,3}$ The direct oxidative threat is not posed by oxygen itself but rather by a series of high energy derivatives of oxygen.

Recently several studies have established the deleterious effect of oxygen free radicals on cellular proteins and enzymes. ${ }^{4,5}$ In such cases hydroxyl radical is generally identified as major damaging species. These hydroxyl radicals are formed from superoxide radical and hydrogen peroxide by a transition metal catalysed Haber Weiss reaction. At the sites where transition metals are bound to protein molecules a localized formation of highly reactive hydroxyl radicals take place leading to an attack on neighbouring amino acid residues.Such damage leads to inactivation of enzymes or fragmentation of proteins. ${ }^{6}$

Erythrocyte membrane cytoskeleton is a protein network lining the inner surface of membrane and composed of three major proteins spectrin, actin and band 4.1. The cytoskeleton is anchored to inner surface of the erythrocyte membrane by interaction with cytoplasmic domain of band 3 protein which is an integral protein of erythrocyte membrane. ${ }^{7}$ Band 3 protein is associated with the movement of anions across the red cell membrane. Membrane cytoskeleton undergoes significant alteration which triggers the removal of aged and damaged cells from circulation. ${ }^{8,9}$ Oxidative damage to erythrocyte or reticulocyte membranes result in an increased lipid peroxidation and crosslinking of proteins. ${ }^{10,11}$ Some workers have shown that oxidatively damaged proteins of red blood cells are rapidly degraded by intra cellular proteolytic system. ${ }^{12,13}$

In this article we present data to emphasize the fact that degradation of erythrocyte membrane proteins from direct attack by free radicals due to radiation injury. We have demonstrated that breakdown of proteins by free radicals occurs both in intact and solubilized erythrocyte membranes.

\section{Materials and Methods}

Acrylamide, bisacrylamide, sodium dodecyl sulphate, coomassie brilliant blue, iodoacetate and glycine were obtained from Sisco Research Laboratory Mumbai. Phenyl methane sulphonyl fluoride was obtained from Sigma Chemical Company. All other chemicals used were of the highest analytical grade available.

Human blood was collected from volunteers after radiotherapy in $3.2 \%$ sodium citrate and from normal healthy volunteers taken as control. Leucocytes and platelets were removed from blood. Erythrocyte ghosts were prepared after hemolysing the red blood cells with $5 \mathrm{mM}$ phosphate buffer $\mathrm{pH}$ 8.0. ${ }^{14}$ The erythrocyte ghosts were suspended in $50 \mathrm{mM}$ phosphate buffer $\mathrm{pH} 7.4$ for further experimentation.

Incubation of erythrocyte ghosts in $50 \mathrm{mM}$ phosphate buffer $\mathrm{pH} 7.4$ was carried out for a period of 4 hours. After the incubation 250 microlitre of sodium dodecyl sulphate sample buffer was added in each tube and the tubes heated in a boiling water bath for 3 minutes. Soduim dodecyl sulphate polyacrylamide gel electrophoresis was carried out immediately in a discontinuous buffer system using $4.5 \%$ stacking and $10 \%$ separating gel. ${ }^{15}$ The gel were stained by coomassie brilliant blue and destained in 5\% methanol and $7.5 \%$ acetic acid.

Protein was estimated by the method of Lowry et al using $1 \%$ SDS to solubilize the membranes. ${ }^{16}$ For 
quantitative estimation of degree of spectrin and band 3 degradation the respective bands were cut from the appropriate lanes and suspended in $25 \%$ pyridine for 24 hours to elute the stain. The coomassie blue colour of the pyridine solution was subsequently measured at 605 $\mathrm{nm}$ by Schimadzu spectrophotometer.

\section{Results}

Results indicated that erythrocyte ghosts after radiotherapy show extensive loss of major protein components. The major proteins of erythrocyte membrane cytoskeleton are clearly seen in membranes unincubated and incubated for 4 hours with buffer taken as control. The loss of major proteins of erythrocyte membrane cytoskeleton are clearly seen in membranes after radiotherapy. There is significant loss of spectrin and band 3 protein without formation of any crosslinking indicating that proteolysis is responsible for degradation caused by oxidative damage with radiation injury. Results presented in Table showed that the loss of spectrin and band 3 protein was 55- 65\%.

Table 1: Quantitation of spectrin and band 3 protein degradation

\begin{tabular}{|c|l|c|}
\hline No. & \multicolumn{1}{|c|}{ Incubation Mixture } & $\begin{array}{c}\text { Absorbance } \\
\text { at 605 nm }\end{array}$ \\
\hline 1. & $\begin{array}{l}\text { Unincubated membranes } \\
\text { (control) }\end{array}$ & 0.057 \\
\hline 2. & $\begin{array}{l}\text { Unincubated membranes } \\
\text { (after radio therapy) }\end{array}$ & 0.037 \\
\hline 3. & $\begin{array}{l}\text { Membranes incubated for } \\
4 \text { hours with buffer } \\
\text { (control) }\end{array}$ & 0.055 \\
\hline 4. & $\begin{array}{l}\text { Membranes incubated for } \\
\text { 4 hours with buffer (after } \\
\text { radio therapy) }\end{array}$ & 0.031 \\
\hline
\end{tabular}

Values were from one representative experiment from a set of three similar experiments

\section{Discussion}

Our data suggests that degradation of oxidatively damaged erythrocyte membrane proteins is due to direct effect of free radical attack with radiation injury. Oxygen free radicals induced damage to erythrocyte membranes leading to crosslinking or degradation of membrane proteins is likely to alter the deformability of red blood cells and enhance the binding of anti-band 3 antibodies. ${ }^{17,18}$ It is possible that in intact membranes crosslinking and proteolysis together contribute to protein damage. Plenty of reports are available indicating damage to red blood cells by oxygen free radicals. Our data focuses attention on alteration of membrane properties of erythrocyte as a result of oxidative damage.
Oxidant stress and exposure to oxygen free radicals cause lipid peroxidation of red cell membranes. The unsaturated fatty acids of phospholipids of biomembranes are attacked by free radical giving rise to fatty acid radical by abstracting the hydrogen atoms. Extensive lipid peroxidation results in membrane disruption and hemolysis. ${ }^{19}$ Apart from damage to membrane phospholipids membrane proteins are also major targets for oxidative damage. The attention has been focused on alteration of membrane properties of erythrocyte as a result of oxidative stress. Some of these changes are crosslinking and aggregation of membrane proteins like spectrin and band 3 proteins, oxidation of $\mathrm{SH}$ group of membrane proteins, possible conformational changes of band 3 , binding of native or denatured hemoglobin to membrane, proteolytic cleavage of band 3 protein and altered surface glycoprotein. ${ }^{20-25}$

The membrane cytoskeleton and in particular spectrin and band 3 protein are major determinants of mechanical and viscoelastic properties of erythrocytes. $^{26}$ Band 3 protein is the predominant integral protein whereas spectrin is most abundant cytoskeletal protein of erythrocyte membrane. The loss of spectrin leads to decreased deformability of red blood cells leading to their sequestration and subsequent removal in splenic sinuses. Our data suggests a direct effect of oxygen free radicals due to radiation injury in damaging the membrane proteins of human erythrocytes. ${ }^{27,28}$ Radiation mainly involves sulfhydryl groups which produces damage to human erythrocyte membrane. ${ }^{29,30}$ Such damage occurs by a site specific formation of hydroxyl radicals by transition metal ions bound to proteins. ${ }^{31}$

It is shown that that senescent cell antigens present in old and damaged erythrocytes have been derived from band 3 protein and these antigens play a role in removal of aged red blood cells from circulation. ${ }^{32,33}$ Oxidative damage and degradation of band 3 protein is likely a mechanism of generation of senescent cell antigen. Further studies are necessary to establish the importance and provide further clues in understanding the various mechanisms of oxidative damage to erythrocyte membrane proteins. However the precise nature of such damage and factors that may inhibit or activate this process have to be investigated.

\section{References}

1. Maestro, R.D. - Systemic consequences of $\mathrm{O} 2$ production: Methods Enzymol 1984,105,386.

2. Brunori, M. and Rotilio, F.- Biochemistry of oxygen radical species. Method Enzymol; 1984, 105, 22.

3. Halliwell, B. and Gutteridge, J.M.C.- Oxygen toxicity, oxygen radicals transition metals and disease Biochem, $\mathrm{J}$. 1984, 219,1

4. Hunt, J.V, Simpsons J.A. and Dean, R.T.- Hydroperoxide mediated fragmentation of proteins, Biochem J. 1988, 250,87 . 
5. Shinar, E, Navok T. and Chevion, M.- The analogous mechanisms of enzymatic inactivation induced by ascorbate and superoxide in the presence of copper J.Biol. Chem 1983, 258, 14778.

6. Marx, G. and Chevion, M.- Site specific modification of albumin by free radicals. Biochem. J. 1985,236,397.

7. Bennett, V.- Proteins involved in membranes cytoskeleton association in human erythrocytes: spectrin, ankyrin and band3. Methods Enzymol.1983,96,313-25.

8. Schluter, K. and Drenckhahn,D. - Co-clustering of denatured hemoglobin with band $3:$ Its role in binding of autoantibodies against band 3 to abnormal and aged erythrocytes. Proc. Natl.Acad.Sci. USA. 1986,83,613141.

9. Suzuki, T.and Dale, G. L. -Membrane proteins in senescent erythrocytes. Biochem. J. 1989,257,37- 41.

10. Hochstein, P. and Jain, S.K. - Association of lipid peroxidation and polymerization of membrane proteins with erythrocyte aging. Fed. Proc. 1981,40, 183.

11. Rice-Evans, C-and Hochstein, P.- Alterations in erythrocyte membrane fluidity by phenyhydrazine induced peroxidation of lipids. Biochem Biophys. Res. Commun. 1981,100,1537.

12. Davies, K.J.A and Goldberg, A.L.- Oxygen radicals stimulate intracellar proteolysis and lipid peroxidation by independent mechanisms in erythrocytes. J.B.ol Chem $1897,262,8220$.

13. Davies, K.J.A and Goldberg, A.L.-Proteins damaged by oxygen radicals are rapidly degraded in extracts of red blood cells. J.Biol Chem. 1987,262,8227.

14. Fairbanks, G, Steck, T.L and Wallach, D.R.H Electrophorectic analysis of major polypeptides of the human erythrocyte membrane. Biochemistry. 1971,10,2607.

15. Laemli, U.K- Cheavage of structural proteins during the assembly of the head of bacteriophage T4. Nature $1970,227,680$.

16. Lowry. O.H, Rosebrough, N., Farr, A.L and Randall, R.J-Protein measurement with the Folin phenol reagent. J. Biol. Chem 1951,193,265.17

17. Beppu, M. Mizukami, A. A., Nagoya, M. and Kikugawa, K. - Binding of antiband 3 autoantibody to oxidatively damaged erythrocytes. J. Biol. Chem. 1990 .265. 3226.18

18. Girotti, A.W. Thomas, S.P. and Jordan, J. E. -Xathine oxidase catalyzed crosslinking of cell membrane proteins. Arch. Biochem Biophys. 1986,251,639.

19. Kunimoto, M, Inoue, K. and Nojima, S-Effect of ferrous iron and ascorbate induced lipid peroxidation on liposomal membranes. Biochem Biophys. Acta 1981,646,169.

20. Shaklai, N. Frayman, B, Fortier, N and Snyder, M.Crosslinking of isolated cystosketal proteins with hemoglobin in a possible damage inflicted to red cell. Biochem. Biophys. Acta. 1987,915,406.

21. Solar, I., Dulitz, J and Shaklai, N. Hemin promoted peroxidation of red cell cytoskeleton proteins. Arch. Biochem Biophys. 1990,283,81.

22. Bennett, V. - The membrane skeleton of human erythrocyte and its implications for more complex cells. Annu. Rev. Biochem. 1985,54,273-304.

23. Low, P.S., Waugh,S.M., Zinke, K. and Drenkahn, D.The role of hemoglobin denaturation and band 3 clustering in red blood cell aging. Science. 1985,227, 531.

24. Reinhart, W.H., Sung, L.A. and Chien,S.- Quantitative relationship between Heinz body formation and red blood cell deformability. Blood. 1986,68,1376.
25. Kannan, R., Labotka,R. and Low, P.S.- Isolation and characterization of the hemichrome -stabilized membrane protein aggregates from sickle erythrocytes. Major site of autologous antibody binding. J. Biol. Chem. 1988, 263, 13766.

26. Jarolim, P. Lahav, M. Liu, S.C. and Palek, J.- Effect of hemoglobin oxidation products on the stability of red cell membrane skeletons and the associations of skeletal proteins : correlation with a release of hemin. Blood. 1990, 76, 2125.

27. Pribush,A.,Agam,G.,YErmiahu,T.,Dvilansky,A.,Meyerste in,D. and Meyerstein,N.-Radiation damage to the erythrocyte membrane : The effects of medium cell concentrations. J. Free Radical Research. 1994,21,135.

28. Meyers, D. K.-Some aspects of radiation effects on cell membranes. Advan. Biol. Med. Phys.1970,13, 219.

29. Shapiro, B. and Koliman, G.-The nature of the membrane injury in irradiated human erythrocytes. Radiation Research. 1968,34,335.

30. Sutherland, R.M., Stannard, J.N. and Weed, R.I.Involvement of sulfhydryl groups radiation produces damage to human erythrocyte membrane. Int. J. Radiat. Bio. Relat. Stud. Phys. Chem. Med. 1967, 12, 551.

31. Chakrabarti, S., Naik, A, A. and Reddy G. R.Phenylhydrazine mediated degradation of bovine serum albumin and membrane proteins of human erythrocytes. Biochem. Biophys. Acta. 1990,1028, 89-94.

32. Kay, M.M.B.-Mechanism of removal of senescent cells by human macrophages Proc. Natl. Acad. Sci. U.S.A. $1975,72,3521$.

33. Kay. M.M.B.-Localisation of senescent cell antigen on band 3. Proc. Natl. Acad. Sci U.S.A 1984,91,5753. 